\title{
Docosahexaenoic acid inhibits the phosphorylation of STAT3 and the growth and invasion of renal cancer cells
}

\author{
SHINSUKE TASAKI ${ }^{1,2}$, AKIO HORIGUCHI ${ }^{1}$, TAKAKO ASANO ${ }^{1}$, \\ KEIICHI ITO ${ }^{1}$, TOMOHIKO ASANO ${ }^{1}$ and HIROTAKA ASAKURA ${ }^{2}$ \\ ${ }^{1}$ Department of Urology, National Defense Medical College, Tokorozawa, Saitama 359-8513; \\ ${ }^{2}$ Department of Urology, Saitama Medical University, Moroyama, Saitama 350-0495, Japan
}

Received October 5, 2015; Accepted January 26, 2017

DOI: 10.3892/etm.2017.4616

\begin{abstract}
Docosahexaenoic acid (DHA) has a variety of anti-tumor activities. The present study examined the anti-tumor activity of DHA in renal cancer cells and its underlying mechanisms of action. The effects of DHA on the viability and proliferation of the human renal cancer cell lines Caki-1 and 786-O were examined by an MTS assay and cell counting. In addition, cell cycle distribution and cell apoptosis were analyzed by flow cytometry and Annexin V staining, and modulation of cell mobility and invasiveness was assessed by wound healing and Matrigel invasion assays. Effects of DHA on intracellular signaling pathways were also analyzed by western blotting. It was observed that DHA significantly reduced the viability and proliferation of Caki-1 and 786-O cells $(\mathrm{P}<0.01)$. Specifically, there were increases in the sub-G1 and G2/M cell populations, as well as the percentages of cells exhibiting Annexin-positive and propidium-iodide-negative staining. In addition, the covered area in a wound and the number of cells invading through a Matrigel chamber decreased when Caki-1 or 786-O cells were treated with DHA. Phosphorylation of epidermal growth factor receptor was also upregulated following DHA treatment, while phosphorylation of signal transducer and activator of transcription 3 and Akt was downregulated. Collectively, these data suggest that DHA may be useful in the treatment of renal cell carcinoma.
\end{abstract}

Correspondence to: Dr Shinsuke Tasaki, Department of Urology, National Defense Medical College, 3-2 Namiki, Tokorozawa, Saitama 359-8513, Japan

E-mail: shinsuketasaki@yahoo.co.jp

Key words: docosahexaenoic acid, kidney cancer, signal transducer and activator of transcription 3, epidermal growth factor receptor, anti-tumor effect

\section{Introduction}

Docosahexaenoic acid (DHA) and eicosapentaenoic acid (EPA) are two distinct forms of omega-3 fatty acids (FAs). Omega-3 FAs are typically found in fish oil and have a general polyunsaturated FA structure with the presence of a double bond at the third carbon (when counting from the methyl end of the chain) (1). Increased consumption of omega-3 FAs has been associated with a lower incidence of various types of cancer, including colon $(2)$, breast $(3,4)$ and prostate cancer $(3,4)$. It has also been demonstrated that omega-3 FAs exert a range of anti-tumor effects, including inhibitory effects on angiogenic mediator production (5), the induction of apoptosis (6), inhibitory effects on tumor invasion and metastasis $(7,8)$ and regulatory effects on signaling pathways (9). In particular, the anti-tumor effects of EPA and DHA have been observed in breast cancer, whereby higher intakes of these FAs are associated with a reduced risk of mortality $(10,11)$. It has also been demonstrated that administration of DHA during anthracyclin-based chemotherapy against metastatic breast cancer improves clinical outcomes, suggesting that omega-3 FA may be an effective adjuvant in the treatment of cancer (12).

Renal cell carcinoma (RCC) represents $\sim 3 \%$ of all adult cancer cases (13). In patients with RCC, $\sim 30 \%$ have metastatic disease at the time of diagnosis, while another $20-30 \%$ develop metastases following surgery (14). Although the treatment options available for metastatic RCC have recently improved due to the clinical development of targeting agents including sorafenib, sunitinib and everolimus (15), metastatic RCC remains a fatal disease. RCC cells originate from the renal proximal tubules and express high levels of multi-drug resistance proteins, thus they are resistant to most forms of chemotherapy. Previous attempts to treat patients with RCC using targeted agents have failed in the majority of cases $(14,16)$. Therefore, studies aiming to identify a novel therapeutic agent to treat patients with metastatic RCC are required. The present study used in vitro techniques including MTS and proliferation assays and flow cytometry analysis to investigate the anti-tumor activities of DHA on the proliferative and invasive capacities of RCC cells at clinically relevant concentrations of $10-200 \mu \mathrm{M}$, as previously determined (17-20). The potential 
roles of signal transducer and activator of transcription 3 (STAT3) signaling in the cellular activities of DHA-treated renal cancer cells were also evaluated.

\section{Materials and methods}

Cell lines and reagents. The human renal cancer cell lines Caki-1 and 786-O were purchased from the American Type Culture Collection (Manassas, VA, USA). DHA was purchased from Cayman Chemical Company (Ann Arbor, MI, USA). Antibodies against epidermal growth factor receptor (EGFR; cat. no. 4267S), phosphorylated (p)-EGFR (p-Tyr1068; cat. no. 2234S), STAT3 (cat. no. 9132S), p-STAT3 (p-Tyr705; cat. no. 9145 L), extracellular signal-regulated kinase (ERK; cat. no. 9102), p-ERK (p-Thr202/Tyr204; cat. no. 9101S), Akt (cat. no. 9272) and p-Akt (p-Ser473; cat. no. 9271; all from Cell Signaling Technology, Inc., Danvers, MA, USA) were used in the present study. Horseradish peroxidase (HRP)-conjugated secondary antibodies and an Amersham Enhanced Chemiluminescence (ECL) Gel system (GE Healthcare Life Sciences, Chalfont, UK) were also used.

Cell viability and proliferation assays. Cell viability was assessed by an MTS assay using a CellTiter $96{ }^{\circledR}$ AQueous Non-Radioactive Cell Proliferation assay kit (Promega Corporation, Madison, WI, USA), as previously described (21). Briefly, cells were seeded into 96 -well plates $\left(3 \times 10^{3}\right.$ cells/well) and following overnight incubation at $37^{\circ} \mathrm{C}$, were treated for $24 \mathrm{~h}$ at $37^{\circ} \mathrm{C}$ with DHA $(0,25,50$ and $100 \mu \mathrm{M})$ prior to addition of MTS solution. The medium used for Caki-1 cells was $1 \mathrm{X}$ minimum essential media (MEM) with $10 \%$ fetal bovine serum (FBS) and the medium for 786-O cells was RPMI medium 1640 with $10 \%$ FBS, both purchased from Gibco; Thermo Fisher Scientific, Inc. (Waltham, MA, USA). At $2 \mathrm{~h}$ post-MTS addition. Prior to the measurement of absorbance, $20 \mu$ l CellTiter $96^{\circledR}$ Aqueous One Solution Reagent per well was added before $2 \mathrm{~h}$ incubation at $37^{\circ} \mathrm{C}$. The absorbance of plates was then measured at a wavelength of $490 \mathrm{~nm}$ with a microplate autoreader. A control group with $0 \mu \mathrm{M}$ DHA were used as a comparison.

Cell proliferation was assessed by counting cell numbers after cells seeded into 6 -well plates $\left(1 \times 10^{4}\right.$ cells/well) had been incubated at $37^{\circ} \mathrm{C}$ with DHA $(0,50,100 \mu \mathrm{M})$ for $0,24,48$ and $72 \mathrm{~h}$. The medium used for Caki-1 cells was 1X MEM with $10 \%$ FBS and the medium for 786-O cells was RPMI medium 1640 with $10 \%$ FBS, as previously stated. Total cell numbers were then counted in four fields using a hemocytometer and mean values were calculated from three replicates. The four fields were the four corners of each square in the nine large squares of the hemocytometer, counted using a CK40 phase contrast microscope (Olympus Corporation, Tokyo, Japan).

Flow cytometry analysis. Cells were incubated for $24 \mathrm{~h}$ with $100 \mu \mathrm{M}$ DHA and a control group with $0 \mu \mathrm{M}$ DHA were used as a comparison. Propidium-iodide (PI)-stained nuclear fractions were obtained and cell cycle data were acquired with a flow cytometer using CellQuest ${ }^{\mathrm{TM}}$ software, version 5.2.1 (BD Biosciences, Franklin Lakes, NJ, USA), following the manufacturer's protocol. Percentages of apoptotic cells were also determined with a fluorescein isothiocyanate-conjugated
Annexin V/PI double-staining assay, using an Annexin V Apoptosis Detection kit (Santa Cruz Biotechnology, Inc., Dallas, TX, USA), as described previously (21).

Cell motility and invasion assay. Cells were grown to 90-100\% confluence on 6-well tissue culture plates. Cells were seeded at $0.3 \times 10^{6}$ in a 6 well flat bottom plate (IWAKI, Co., Ltd., Hong Kong, China) with MEM (1X) with 10\% FBS and RPMI 1640 (1X) with 10\% FBS for Caki-1 and 786-O cells, respectively. A wound was then made by scraping the middle of the cell monolayer with a P200 pipette tip, as previously described (21). After floating cells were removed following an extensive wash with $1 \mathrm{ml}$ ice-cold phosphate-buffered saline, fresh complete MEM and RPMI medium supplemented with DHA was added to each type of cell, as previously detailed. Following $12 \mathrm{~h}$, cell migration and movements throughout the wound area were observed using a CK40 phase contrast microscope (Olympus Corporation, Tokyo, Japan). ImageJ software version 1.46 (National Institutes of Health, Bethesda, MA, USA) was used to analyze the images.

Cell invasion was evaluated using a Matrigel-coated Transwell system in 24-well plates including a membrane with $8-\mu \mathrm{m}$ pores (BD Biosciences), as described previously (21). Briefly, $2 \times 10^{5}$ cells suspended in $500 \mu \mathrm{l}$ serum-free medium (MEM and RPMI, as previously detailed) were added to the insert and $750 \mu \mathrm{l}$ serum-free medium with the indicated concentration of DHA $(0,25,50$ and $100 \mu \mathrm{M})$ was added to the bottom of the well. Following incubation for $24 \mathrm{~h}$ at $37^{\circ} \mathrm{C}$, the inserts were fixed in $100 \%$ methanol, then filters were stained with $1 \%$ toluidine blue in $1 \%$ borax for $10 \mathrm{~min}$. Cells that had invaded through the Matrigel-coated Transwell inserts were counted at a magnification of $x 400$. Numbers of cells in at least 10 randomly selected fields/wells were counted in three independent experiments.

Western blot analysis. Cells at a density of $2 \times 10^{6}$ were treated with 0 (control), 50 and $100 \mu \mathrm{M}$ DHA for $6 \mathrm{~h}$, then lysed in radioimmunoprecipitation assay buffer composed of $10 \mathrm{mM}$ tris-HCl (Nacalai Tesque, Inc., Kyoto, Japan), $150 \mathrm{mM} \mathrm{NaCl}$ (Kanto Chemical, Co., Inc., Tokyo, Japan), 1\% Triton X-100 (MP Biomedicals LLC, Santa Ana, CA, USA), $5 \mu \mathrm{M}$ ethylenediaminetetra acetic acid (Nacalai Tesque, Inc.), $1 \%$ sodium deoxycholate (Difco; BD Biosciences, San Jose, CA, USA), $0.1 \%$ sodium dodecyl sulfate, $1.2 \%$ aprotinin, $5 \mu \mathrm{M}$ leupeptin, $4 \mu \mathrm{M}$ antipain, $1 \mathrm{mM}$ phenylmethylsulfonyl fluoride and $0.1 \mathrm{mM} \mathrm{Na}_{3} \mathrm{VO}_{4}$ (all; Sigma Aldrich; Merck KGaA, Darmstadt, Germany) according to a previously described method (21). Samples were centrifuged at $16,000 \mathrm{x} g$ for $20 \mathrm{~min}$ at $4^{\circ} \mathrm{C}$. The amount of protein was quantified using the DC protein assay kit (BD Biosciences) according to the manufacturers protocol. Equal amounts $(50 \mu \mathrm{l})$ of resulting lysates were separated using a $10 \%$ SDS-PAGE gel and transferred to nitrocellulose membranes. Membranes were then blocked at room temperature with 5\% skimmed milk and tris-buffered saline and Tween-20 solution for $1 \mathrm{~h}$. The membranes were then incubated at $4^{\circ} \mathrm{C}$ overnight with primary antibodies, then incubated at room temperature for $1 \mathrm{~h}$ with the corresponding secondary antibody (Rabbit Ig HRP-linked Whole Ab, from Donkey; NA934-1ML; GE Healthcare Japan Corporation, Tokyo, Japan) at a 1:5,000 


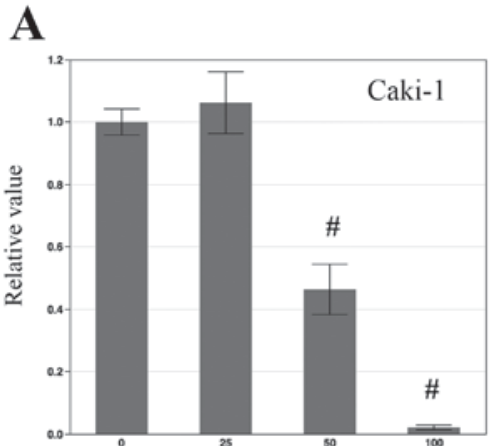

$\operatorname{DHA}(\mu \mathrm{M})$

B

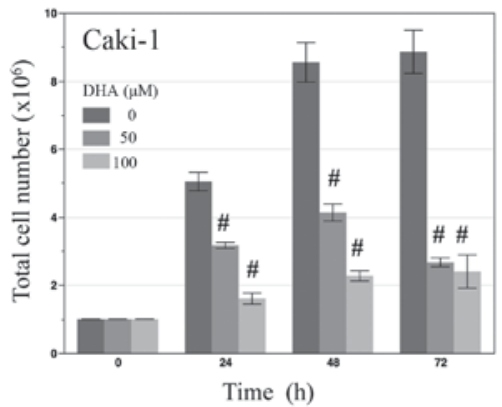

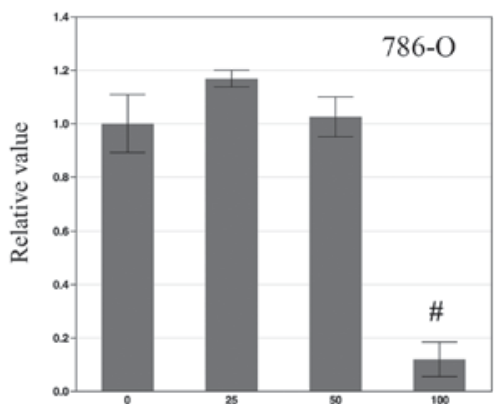

DHA $(\mu \mathrm{M})$

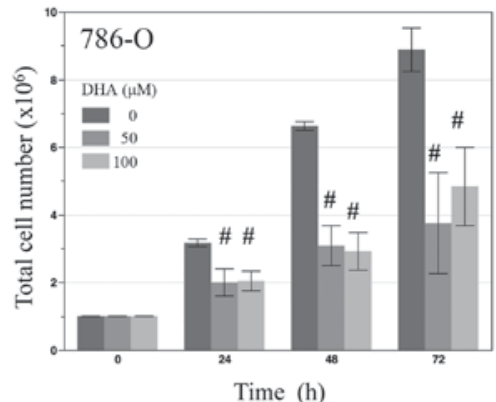

Figure 1. Effects of DHA on the viability and proliferation of renal cancer cells. (A) An MTS assay was performed to determine the viability of Caki-1 and $786-\mathrm{O}$ cells following treatment with 25,50 and $100 \mu \mathrm{M}$ DHA for $24 \mathrm{~h}$. Cell viability was significantly decreased in Caki-1 cells treated with 50 and $100 \mu \mathrm{M}$ DHA and 786-O cells treated with $100 \mu \mathrm{M}$. (B) Total cell counts as a measure of proliferation were determined in Caki-1 and 786-O cells following treatment with 25,50 and $100 \mu \mathrm{M}$ DHA for 24, 48 and $72 \mathrm{~h}$. Proliferation was significantly lower in both cell lines at all doses of DHA relative to controls at corresponding time points. ${ }^{\#} \mathrm{P}<0.01$ vs. untreated control cells of respective cell lines. DHA, docosahexaenoic acid; Caki-1 and 786-O, renal cancer cell lines.

dilution. Immunolabelled proteins were subsequently visualized by enhanced chemiluminescence with an Amersham ECL Gel System, according to the manufacturer's protocol.

Statistical analysis. Data are presented as the mean \pm standard error of the mean of three independent experiments. One way analysis of variance followed by a protected Fisher's least significant difference post hoc test was used to analyze continuous data. The statistical significance of differences was evaluated using a paired t-test and $\mathrm{P}<0.05$ was considered to indicate a statistically significant difference. JMP version 9 was used to assess all data (SAS Institute, Inc., Cary, NC, USA).

\section{Results}

DHA inhibits the growth of renal cancer cells by inducing apoptosis. To determine the effect of DHA on the proliferation of renal cancer cells in vitro, the renal cancer cell lines Caki-1 and 786-O were treated with various concentrations of DHA $(0,25,50$ and $100 \mu \mathrm{M})$ for $24 \mathrm{~h}$ prior to an MTS cell viability assay. In Caki-1 cells, treatment with 50 and $100 \mu \mathrm{M}$ DHA led to significant decreases in cell viability (both $\mathrm{P}<0.01$; Fig. $1 \mathrm{~A}$ ), while in $786-\mathrm{O}$ cells, only $100 \mu \mathrm{M}$ DHA induced a significant decrease in cell viability compared with the control $(\mathrm{P}<0.01$; Fig. 1A). To determine total cell numbers, Caki-1 and 786-O cells were counted following treatment with $0,50,100 \mu \mathrm{M}$ DHA for 24,48 and $72 \mathrm{~h}$. At each time point, total numbers of DHA-treated cells were significantly lower than those of untreated control cells (all $\mathrm{P}<0.01$; Fig. 1B).

To determine whether the inhibitory action of DHA on cell proliferation was due to apoptosis-inducing effects, Caki-1 and 786-O cells were treated with $100 \mu \mathrm{M}$ DHA for $24 \mathrm{~h}$ prior to cell cycle analysis by flow cytometry. Following treatment with DHA, it was observed that the sub-G1 populations of Caki-1 and 786-O cells (37.44 and $16.46 \%$, respectively) were greater than those of untreated controls $(7.09 \%$ in Caki-1 and $6.26 \%$ in 786-O control cells: Fig. 2A). DHA-treated cell lines were also double stained with Annexin V and PI and analyzed by flow cytometry. Following treatment with $100 \mu \mathrm{M}$ DHA, it was observed that the percentages of Annexin-positive and PI-negative (apoptotic) cells in both the Caki-1 and 786-O cell lines were increased (18.81 and 9.92\%, respectively), relative to untreated controls $(0.22 \%$ in Caki- 1 and $0.14 \%$ in $786-\mathrm{O}$ control cells; Fig. 2B). Collectively, these data suggest that DHA inhibits the growth of renal cancer cells through the induction of apoptosis.

DHA inhibits cell motility and invasiveness of renal cancer cells. The effects of DHA on the migration and invasion of renal cancer cells were also evaluated by a wound scratch assay. Monolayers of Caki-1 and 786-O cells were disrupted to create a uniform wound and grown for $12 \mathrm{~h}$ with $0,25,50$, $100 \mu \mathrm{M}$ DHA. In both cell lines, treatment with 50 and $100 \mu \mathrm{M}$ DHA lead to significant decreases in the area covered by cells, relative to that of untreated controls (Fig $3 \mathrm{~A}$ and $\mathrm{B} ; \mathrm{P}<0.001$ ). Similarly, in Matrigel invasion assays, DHA treatment $(25,50$ 
A

Caki-1
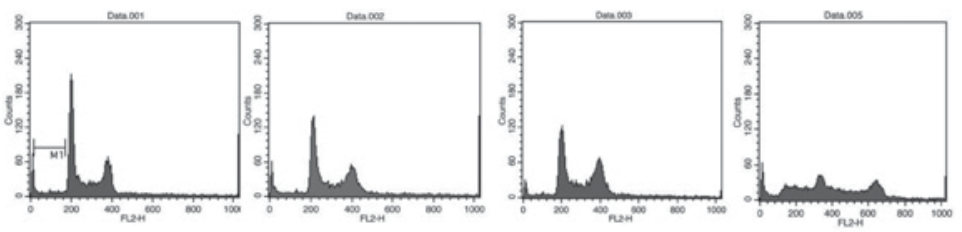

$786-\mathrm{O}$
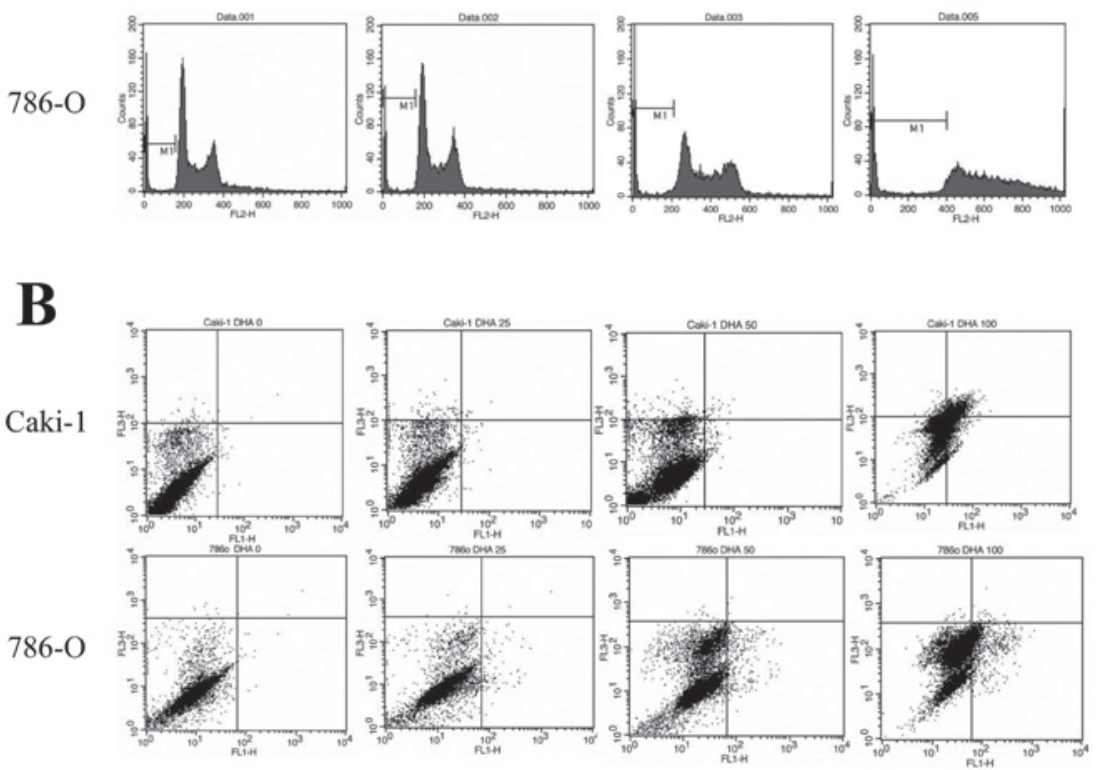

Figure 2. Effects of DHA on cell cycle progression and apoptosis. (A) Cell cycle distribution of Caki-1 and 786-O cells treated with $0,25,50$ and $100 \mu \mathrm{M}$ DHA for $24 \mathrm{~h}$. In both cell lines the population of cells in the sub-G1 phase was increased by DHA treatment (B) Annexin V/propidium iodide double-staining of Caki-1 and 786-O cells to determine rates of apoptosis following treatment with 0,25, 50 and $100 \mu \mathrm{M}$ DHA for $24 \mathrm{~h}$. Cells that exhibited ' V-positive and propidium-iodide-negative staining (early apoptotic) are shown as a percentage on each graph. DHA, docosahexaenoic acid; Caki-1 and 786-O, renal cancer cell lines.

and $100 \mu \mathrm{M})$ significantly decreased the invasive properties of both cell lines (Fig. 3C and D; $\mathrm{P}<0.001$ ). In particular, there were markedly low numbers of invaded cells following treatment with 50 and $100 \mu \mathrm{M}$ DHA. These results indicate that DHA may suppress the migration and invasion of renal cancer cells.

DHA alters EGFR phosphorylation status and STAT3 signaling. Potential signaling pathways underlying the anti-tumor activity of DHA in renal cancer cells were subsequently investigated. Caki-1 and 786-O cells lysates were subjected to western blotting following incubation of cells for $6 \mathrm{~h}$ in the presence or absence of DHA (50 and $100 \mu \mathrm{M}$; Fig. 4). Previous studies have demonstrated that DHA is incorporated into cellular membranes, where it may alter the localization and function of EGFR by disrupting its association with membrane lipid raft microdomains (9). Furthermore, it has been documented that EGFR is overexpressed in RCC (22). In Caki- 1 and 786-O cells, DHA treatment markedly increased the phosphorylation of EGFR in a dose-dependent manner, though had no observable effect on EGFR expression (Fig. 4). The phosphorylation of key signaling molecules downstream of EGFR, namely STAT3, Akt and ERK, was also evaluated. Levels of p-STAT3 and p-Akt in both cell lines were decreased by DHA in a dose-dependent manner (Fig. 4). However DHA had no discernable effect on the levels of STAT3 and Akt. Furthermore, DHA treatment had little effect on the levels of ERK or p-ERK (Fig. 4).

\section{Discussion}

In the present study, DHA inhibited the proliferation and invasion of renal cancer cells in vitro, possibly through regulatory effects on the functions of EGFR, STAT3 and Akt. A previous study in Japan documented that the mean concentration of serum DHA in healthy controls was $18.52 \mathrm{mg} / \mathrm{dl}(563.0 \mu \mathrm{M}) \quad(17)$ and previous studies investigating the anti-tumor effects of DHA on colon (18), breast (19) and prostate cancer cells in vivo (20) have used DHA concentrations between 10 and $200 \mu \mathrm{M}$. Therefore, the present study used DHA concentrations $\leq 100 \mu \mathrm{M}$ to obtain clinically relevant results.

Results from epidemiological and preclinical studies suggest that omega-3 FAs, including DHA, reduce the incidence of various types of cancer $(1,3,4,23)$. In a mouse model of breast cancer, tumor size was reduced significantly by dietary DHA in a dose-dependent manner (24). Indeed, DHA has been documented to have a range of anti-tumor effects, including inhibitory effects on tumor angiogenesis (5), apoptosis-inducing activity (6), inhibitory effects on tumor invasion and metastasis $(7,8)$ and regulatory effects on signaling pathways (9). In addition, it has been documented that serum levels of omega-3 FAs in patients with pancreatic cancer, lung cancer or non-Hodgkin lymphoma were lower than those in healthy controls $(25,26)$, with the lowest levels observed in patients with more advanced-stage cancer $(26,27)$. It has also been demonstrated that DHA reduces metastasis in animal models 

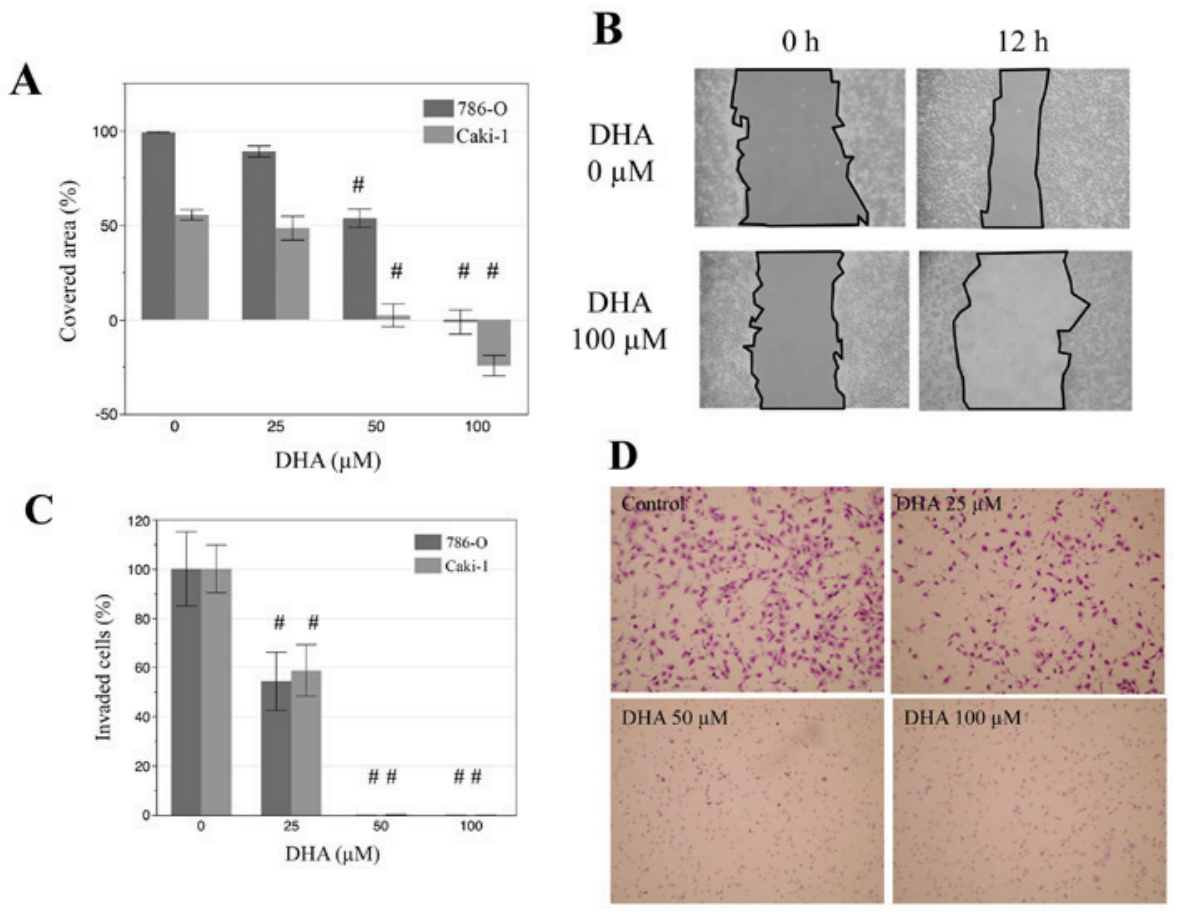

Figure 3. DHA suppresses the migration and invasion of renal cancer cells. (A) Wound healing data obtained from disruption of Caki-1 and 786-O cell monolayers with a pipette tip following treatment with $0,25,50$ and $100 \mu \mathrm{M}$ DHA for $12 \mathrm{~h}$. (B) Representative photomicrographs showing wound closure in Caki-1 cells. Magnification x200. (C) Data obtained from a Matrigel invasion assay of Caki-1 and 786-O cells after incubation with DHA (0, 25, 50 and $100 \mu \mathrm{M}$ ) for $24 \mathrm{~h}$. (D) Representative photomicrographs indicating Caki-1 cell invasion, magnification $\mathrm{x} 100 .{ }^{.} \mathrm{P}<0.001$ vs. untreated control cells of respective cell lines. DHA, docosahexaenoic acid; Caki-1 and 786-O, renal cancer cell lines.

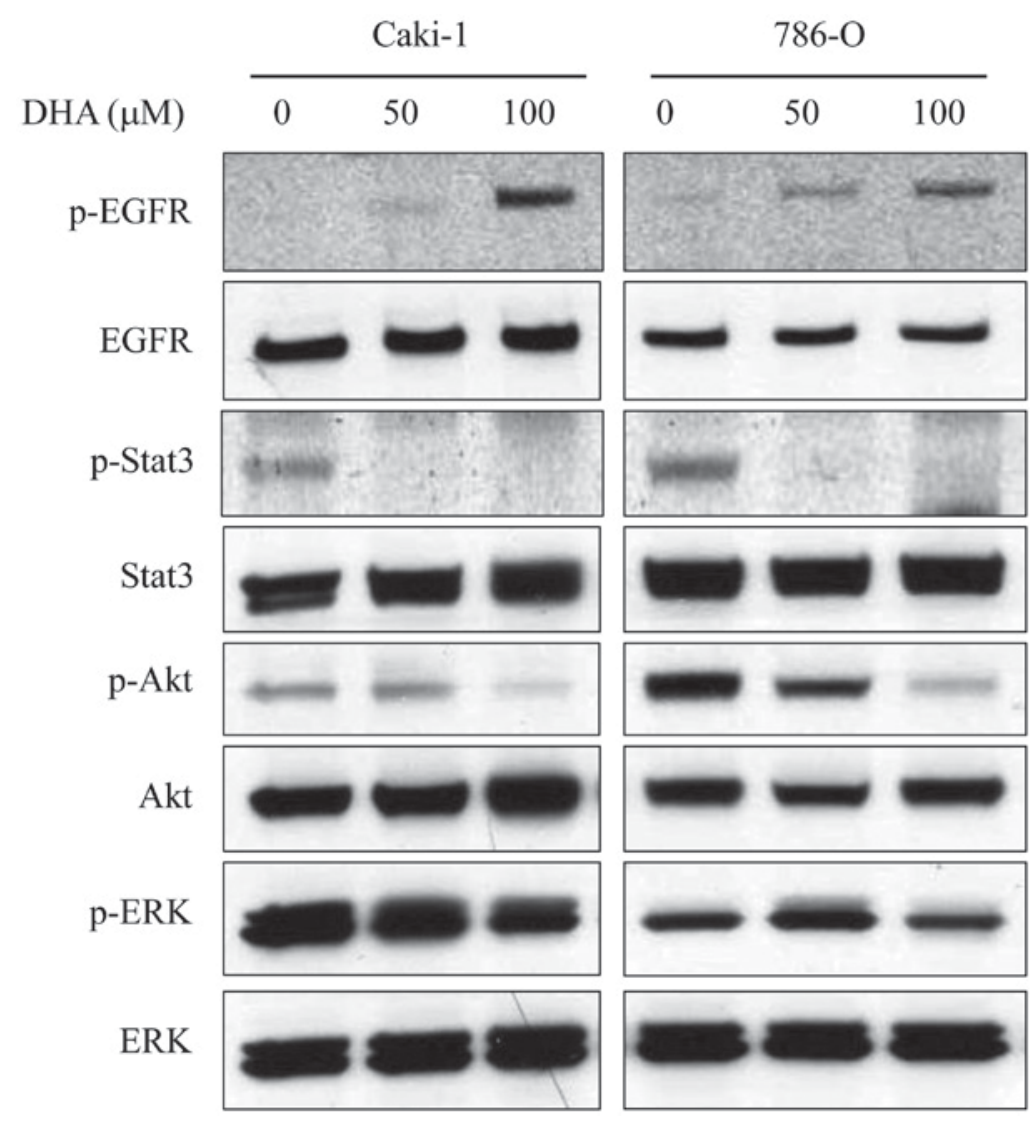

Figure 4. Effects of DHA on intracellular signaling pathways. Western blotting was performed to detect the phosphorylation of intracellular signaling molecules (EGFR, STAT3, Akt and ERK) in Caki-1 and 786-O cells following treatment with 0,50 and $100 \mu \mathrm{M}$ DHA for $6 \mathrm{~h}$. In both cell lines, DHA treatment markedly increased the phosphorylation of EGFR in a dose-dependent manner while downregulating the phosphorylation of STAT3 and Akt. DHA treatment had little effect on the phosphorylation of ERK. DHA, docosahexaenoic acid; Caki-1 and 786-O, renal cancer cell lines; EGFR, epidermal growth factor receptor; STAT3, signal transducer and activator of transcription 3; ERK, extracellular signal-regulated protein kinase. 
using mice $(7,8)$ and prevents the migration and invasion of human MDA-MB-231 mammary cancer cells in vitro (7). Diets high in DHA-rich fish oil prevent breast cancer metastasis to the bone by reducing the expression of cluster of differentiation 44, regarded as a typical molecular signature of cancer stem cells (7). Furthermore, in a mouse model of Lewis lung carcinoma, DHA metabolites were found to inhibit vascular endothelial growth factor- and fibroblast growth factor-induced angiogenesis and suppress primary tumor growth and metastasis (8). Since previous studies have identified an association between omega-3 FAs and cancer development, the present study investigated whether DHA serves a role in the progression and/or metastasis of RCC. DHA is incorporated into cellular membranes and may disrupt lipid raft microdomains that act as detergent-resistant signaling platforms (28), thus leading to a disruption in signaling pathways associated with numerous cancers, including EGFR signaling (9). EGFR is a transmembrane receptor tyrosine kinase and its overexpression is frequently observed in RCC (22). Activation of EGFR stimulates downstream signaling pathways that have been implicated in the regulation of tumor growth, invasion and metastasis (29). However, membrane localization of EGFR is essential for its modulatory effects on downstream signaling pathways, and previous studies have indicated that DHA displaces EGFR from lipid rafts, thus leading to a subsequent decrease in its downstream signaling activity (9). Analogous to previous findings, the present study observed that DHA treatment led to changes in the phosphorylation status of EGFR and its downstream signaling pathways in renal cancer cells. It has previously been observed that STAT3 and Akt are constitutively activated in RCC patients, particularly in those with metastatic diseases $(30,31)$. In turn, constitutively activated Akt in renal cancer cells may confer cellular resistance to the EGFR inhibitor gefitinib (32). The present study demonstrated that DHA inhibited the activation of STAT3 and Akt in a dose-dependent manner. As the STAT3 and Akt pathways serve a key role in apoptosis, cell migration and invasion $(30,31)$, these data suggest that these pathways serve a role in cancer progression.

In conclusion, similar to results from previous preclinical and clinical studies investigating a range of cancers, the present results suggest that DHA may be a potential therapeutic agent for the treatment of renal carcinoma. However, applications of the present findings are limited, due to a lack of in vivo and clinical data regarding RCC. Therefore, future clinical studies into the efficacy of DHA in preventing RCC metastasis are necessary.

\section{References}

1. Larsson SC, Kumlin M, Ingelman-Sundberg M and Wolk A: Dietary long-chain n-3 fatty acids for the prevention of cancer: A review of potential mechanisms. Am J Clin Nutr 79: 935-945, 2004.

2. Sasazuki S, Inoue M, Iwasaki M, Sawada N, Shimazu T, Yamaji T, Takachi R and Tsugane S; Japan Public Health Center-Based Prospective Study Group: Intake of n-3 and n-6 polyunsaturated fatty acids and development of colorectal cancer by subsite: Japan public health center-based prospective study. Int J Cancer 129: 1718-1729, 2011

3. Terry PD, Rohan TE and Wolk A: Intakes of fish and marine fatty acids and the risks of cancers of the breast and prostate and of other hormone-related cancers: A review of the epidemiologic evidence. Am J Clin Nutr 77: 532-543, 2003.
4. Sonoda T, Nagata Y, Mori M, Miyanaga N, Takashima N, Okumura K, Goto K, Naito S, Fujimoto K, Hirao Y, et al: A case-control study of diet and prostate cancer in Japan: Possible protective effect of traditional Japanese diet. Cancer Sci 95: 238-242, 2004.

5. Spencer L, Mann C, Metcalfe M, Webb M, Pollard C, Spencer D, Berry D, Steward W and Dennison A: The effect of omega-3 FAs on tumour angiogenesis and their therapeutic potential. Eur J Cancer 45: 2077-2086, 2009.

6. Serini S, Trombino S, Oliva F, Piccioni E, Monego G, Resci F, Boninsegna A, Picci N, Ranelletti FO and Calviello G: Docosahexaenoic acid induces apoptosis in lung cancer cells by increasing MKP-1 and down-regulating p-ERK1/2 and p-p38 expression. Apoptosis 13: 1172-1183, 2008.

7. Mandal CC, Ghosh-Choudhury T, Yoneda T, Choudhury GG and Ghosh-Choudhury N: Fish oil prevents breast cancer cell metastasis to bone. Biochem Biophys Res Commun 402: 602-607, 2010.

8. Zhang G, Panigrahy D, Mahakian LM, Yang J, Liu JY, Stephen Lee KS, Wettersten HI, Ulu A, Hu X, Tam S, et al: Epoxy metabolites of docosahexaenoic acid (DHA) inhibit angiogenesis, tumor growth, and metastasis. Proc Natl Acad Sci USA 110: 6530-6535, 2013.

9. Rogers KR, Kikawa KD, Mouradian M, Hernandez K, McKinnon KM, Ahwah SM and Pardini RS: Docosahexaenoic acid alters epidermal growth factor receptor-related signaling by disrupting its lipid raft association. Carcinogenesis 31: 1523-1530, 2010.

10. Patterson RE, Flatt SW, Newman VA, Natarajan L, Rock CL, Thomson CA, Caan BJ, Parker BA and Pierce JP: Marine fatty acid intake is associated with breast cancer prognosis. J Nutr 141: 201-206, 2011.

11. Vaughan VC, Hassing MR and Lewandowski PA: Marine polyunsaturated fatty acids and cancer therapy. Br J Cancer 108: 486-492, 2013

12. Bougnoux P, Hajjaji N, Ferrasson MN, Giraudeau B, Couet C and Le Floch O: Improving outcome of chemotherapy of metastatic breast cancer by docosahexaenoic acid: A phase II trial. Br J Cancer 101: 1978-1985, 2009.

13. Jemal A, Siegel R, Ward E, Hao Y, Xu J, Murray T and Thun MJ: Cancer statistics, 2008. CA Cancer J Clin 58: 71-96, 2008.

14. Bukowski RM: Prognostic factors for survival in metastatic renal cell carcinoma: Update, 2008. Cancer 115 (10 Suppl): S2273-S2281, 2009

15. Linehan WM, Srinivasan R and Schmidt LS: The genetic basis of kidney cancer: A metabolic disease. Nat Rev Urol 7: 277-285, 2010.

16. Sonpavde G and Choueiri TK: Biomarkers: The next therapeutic hurdle in metastatic renal cell carcinoma. Br J Cancer 107: 1009-1016, 2012.

17. Ghadimi R, Kuriki K, Tsuge S, Takeda E, Imaeda N, Suzuki S, Sawai A, Takekuma K, Hosono A, Tokudome Y, et al: Serum concentrations of fatty acids and colorectal adenoma risk: A case-control study in Japan. Asian Pac J Cancer Prev 9: 111-118, 2008.

18. Horiguchi A, Asano T, Ito K, Sumitomo M and Hayakawa M: Pharmacological inhibitor of fatty acid synthase suppresses growth and invasiveness of renal cancer cells. J Urol 180: 729-736, 2008

19. Calviello G, Resci F, Serini S, Piccioni E, Toesca A, Boninsegna A, Monego G, Ranelletti FO and Palozza P: Docosahexaenoic acid induces proteasome-dependent degradation of beta-catenin, down-regulation of survivin and apoptosis in human colorectal cancer cells not expressing COX-2. Carcinogenesis 28: 1202-1209, 2007.

20. Kang KS, Wang P, Yamabe N, Fukui M, Jay T and Zhu BT: Docosahexaenoic acid induces apoptosis in MCF-7 cells in vitro and in vivo via reactive oxygen species formation and caspase 8 activation. PLoS One 5: e10296, 2010.

21. Hu Y, Sun H, Owens RT, Gu Z, Wu J, Chen YQ, O'Flaherty JT and Edwards IJ: Syndecan-1-dependent suppression of PDK1/Akt/bad signaling by docosahexaenoic acid induces apoptosis in prostate cancer. Neoplasia 12: 826-836, 2010.

22. Minner S, Rump D, Tennstedt P, Simon R, Burandt E, Terracciano L, Moch H, Wilczak W, Bokemeyer C, Fisch M, et al: Epidermal growth factor receptor protein expression and genomic alterations in renal cell carcinoma. Cancer 118: 1268-1275, 2012.

23. Sawada N, Inoue M, Iwasaki M, Sasazuki S, Shimazu T, Yamaji T, Takachi R, Tanaka Y, Mizokami M and Tsugane S; Japan Public Health Center-Based Prospective Study Group: Consumption of n-3 fatty acids and fish reduces risk of hepatocellular carcinoma. Gastroenterology 142: 1468-1475, 2012. 
24. El-Mesery M, Al-Gayyar M, Salem H, Darweish M and El-Mowafy A: Chemopreventive and renal protective effects for docosahexaenoic acid (DHA): Implications of CRP and lipid peroxides. Cell Div 4: 6, 2009.

25. Zuijdgeest-van Leeuwen SD, van der Heijden MS, Rietveld T, van den Berg JW, Tilanus HW, Burgers JA, Wilson JH and Dagnelie PC: Fatty acid composition of plasma lipids in patients with pancreatic, lung and oesophageal cancer in comparison with healthy subjects. Clin Nutr 21: 225-230, 2002.

26. Cvetković Z, Vucić V, Cvetković B, Petrović M, Ristić-Medić D, Tepsić J and Glibetić M: Abnormal fatty acid distribution of the serum phospholipids of patients with non-Hodgkin lymphoma. Ann Hematol 89: 775-782, 2010.

27. Macášek J, Vecka M, Žák A, Urbánek M, Krechler T, Petruželka L, Staňková B and Zeman M: Plasma fatty acid composition in patients with pancreatic cancer: Correlations to clinical parameters. Nutr Cancer 64: 946-955, 2012.
28. Pike LJ: Rafts defined: A report on the keystone symposium on lipid rafts and cell function. J Lipid Res 47: 1597-1598, 2006.

29. Kalyankrishna S and Grandis JR: Epidermal growth factor receptor biology in head and neck cancer. J Clin Oncol 24: 2666-2672, 2006.

30. Horiguchi A, Oya M, Shimada T, Uchida A, Marumo K and Murai M: Activation of signal transducer and activator of transcription 3 in renal cell carcinoma: A study of incidence and its association with pathological features and clinical outcome. J Urol 168: 762-765, 2002.

31. Horiguchi A, Oya M, Uchida A, Marumo K and Murai M: Elevated Akt activation and its impact on clinicopathological features of renal cell carcinoma. J Urol 169: 710-713, 2003.

32. Kuroda K, Horiguchi A, Sumitomo M, Asano T, Ito K, Hayakawa $\mathrm{M}$ and Asano T: Activated Akt prevents antitumor activity of gefitinib in renal cancer cells. Urology 74: 209-215, 2009. 